\title{
Perinatal exposure to low-dose bisphenol $A$ affects the neuroendocrine stress response in rats
}

\author{
Emily Panagiotidou', Sophia Zerva ${ }^{2}$, Dimitra J Mitsiou ${ }^{2}$, Michael N Alexis ${ }^{2}$ and \\ Efthymia Kitraki ${ }^{1}$ \\ ${ }^{1}$ Department of Basic Sciences and Oral Biology, School of Dentistry, National and Kapodistrian \\ University of Athens, Thivon 2, 11527 Athens, Greece \\ ${ }^{2}$ Institute of Biology, Medicinal Chemistry and Biotechnology, National Hellenic Research Foundation, \\ 48, Vassileos Constantinou Avenue, 11635 Athens, Greece
}

\author{
Correspondence \\ should be addressed \\ to E Kitraki \\ Email \\ ekitraki@dent.uoa.gr
}

\begin{abstract}
Bisphenol A (BPA) is an estrogen-mimicking endocrine disruptor. Early-life exposures to low doses of BPA exert long-lasting effects on animals' reproductive and brain physiology. However, little is known about the effects of BPA on the stress-response system. Given the interaction of sex and stress hormones, we examined the effect of a low perinatal BPA exposure on the function of the hypothalamic-pituitary-adrenal (HPA) axis at rest and upon application of acute stress. Throughout pregnancy and lactation rats received daily $40 \mu \mathrm{g}$ $\mathrm{BPA} / \mathrm{kg}$ body weight orally via cornflakes. We studied the effect of this low but chronic exposure to BPA in the male and female offspring at puberty. BPA exposure led to abnormal adrenal histology including reduced zona reticularis especially in male offspring, hyperplasia of zona fasciculata in both sexes, and increased adrenal weight in female offspring. BPA-treated females had increased basal corticosterone and reduced hypothalamic glucocorticoid receptors (GR) levels. Stressed BPA-exposed females exhibited anxiety-like behavioral coping, a less rigorous corticosterone response, and did not downregulate GR in the hypothalamus, compared with control females. BPA-exposed males exhibited a heightened corticosterone stress response compared with females; they also displayed increased pro-opiomelanocortin mRNA levels and retained the prestress levels of pituitary corticotropin-releasing hormone-receptor 1, compared with control males. We found that perinatal chronic exposure to a low dose of BPA perturbs the basal and stress-induced activity of the HPA axis in a sexually dimorphic manner at adolescence. Exposure to BPA might contribute to increased susceptibility to stress-related disorders in later life.
\end{abstract}

\section{Key Words}

- adrenal cortex

- bisphenol A

- glucocorticoid receptor

- HPA axis

- rat

\section{Introduction}

The hypothalamus-pituitary-adrenal (HPA) axis plays a pivotal role in the neuroendocrine stress response. Glucocorticoids (corticosterone in rodents, cortisol in humans), synthesized mainly in the zona fasciculata of the adrenal cortex, are massively released into the circulation shortly after stress, in response to adrenocorticotropin http://joe.endocrinology-journals.org DOI: 10.1530/JOE-13-0416
(C) 2014 Society for Endocrinology Printed in Great Britain
Published by Bioscientifica Ltd 
(ACTH) that is rapidly secreted by pituitary corticotrophs upon stimulation by the hypothalamic-corticotropinreleasing hormone (CRH; Carrasco \& Van de Kar 2003). CRH-receptor 1 (CRHR1) in the pituitary is also considered to be indispensable for the release of glucocorticoids from the adrenal cortex (Müller et al. 2001). The released glucocorticoids initially potentiate the stress response and subsequently terminate the HPA axis activation by exerting negative feedback at the levels of the pituitary, the hypothalamus, and in some extra-hypothalamic brain structures. Glucocorticoid receptors (GR), the classical nuclear receptors for corticosteroids, mainly mediate the negative feedback toward termination of the stress response and return to homeostasis (Joëls et al. 2012).

Deviations from normal HPA function have been linked to psychopathologies including affective, neurodegenerative, and cognitive disorders (de Kloet et al. 2005a). A substantial number of these pathologies may originate during development. The prenatal and earlypostnatal periods constitute the most critical time windows for an aberrant HPA programming by maternally derived or environmental factors (de Kloet et al. 2005b, Szyf et al. 2005, Weinstock 2008). Gonadal steroids also exert organizational effects on the HPA axis that establish sex differences in the axis components in adulthood (Patchev et al. 1995, Seale et al. 2005). The effects of phytoestrogens and environmental estrogens (xenoestrogens) on the HPA axis have not been studied extensively. Early-life exposure of rats to the soy isoflavone genistein (Ohno et al. 2003) or to nonylphenol (Chang et al. 2012) reportedly modified adrenal steroidogenesis and corticosterone secretion in animals' later life.

Bisphenol A (BPA) is a selective modulator of estrogen receptors. It is utilized for the production of plastics and epoxy resins, used in lining food cans and for some dental materials, as well as for many other everyday life products and therefore is widely present in our environment. BPA has been detected in more than $90 \%$ of the human tissues samples examined and there is increased concern regarding its higher bioaccumulation in fetal and infant tissues (Calafat et al. 2008). The dose of $50 \mathrm{mg} \mathrm{BPA} / \mathrm{kg}$ per day has been determined to be the lowest-observable-adverse-effect level (LOAEL) dose and the reference dose of $50 \mu \mathrm{g} \mathrm{BPA} / \mathrm{kg}$ body weight as the safe daily exposure for humans (Vandenberg et al. 2009). However, the safety of this dose has been strongly disputed due to the increasing number of animal studies reporting adverse effects upon low exposures (Welshons et al. 2006). Importantly, developmental exposures have been reported to exert programming effects in the rodent brain, including alterations in sexually dimorphic brain areas (Kubo et al. 2003, Funabashi et al. 2004), behavior (Farabollini et al. 1999, Kubo et al. 2001, Kawai et al. 2003, Rubin et al. 2006), cognitive skills (Carr et al. 2003, Miyagawa et al. 2007, Xu et al. 2007), and levels of estrogen receptors (Khurana et al. 2000). Published human data are also associating neurobehavioral problems in children with maternal levels of BPA during pregnancy (Braun et al. 2009, 2011, Perera et al. 2012).

Sex hormones interact with the stress response system (Handa et al. 1994, Viau \& Meaney 1996, Viau 2002). First indications that glucocorticoids and their actions in the brain are sensitive to programming effects of BPA have been derived from our previous work (Poimenova et al. 2010), showing alterations in circulating corticosterone and its hippocampal receptors, along with impaired spatial recognition memory of exposed rats. Considering that this cognitive task is a kind of mild stress, the altered neuroendocrine responses of BPA litters after the task was suggestive of a BPA effect on stress response. The aim of this study was to further examine the potential effects of chronic perinatal BPA exposure on the HPA axis response under basal conditions and following acute stress. Specific objectives included investigation of BPA-induced effects on behavioral coping and on all compartments of the HPA axis of exposed rats at mid-puberty, namely, on adrenal morphology and corticosterone secretion, on hypothalamic-GR protein levels, as well as on pituitary Crhr1 and pro-opiomelanocortin (Pomc) mRNA levels.

\section{Materials and methods}

\section{Animals and experimental design}

Female Wistar rats (10 weeks old) were used for breeding. Pregnancy was determined by vaginal smears and pregnant animals were randomly assigned into either the control or the BPA group ( $n=5$ in each) and were housed individually under constant photoperiod cycle $(12 \mathrm{~h}$ light: $12 \mathrm{~h}$ darkness) and room temperature $\left(22 \pm 2{ }^{\circ} \mathrm{C}\right)$, having free access to normal chow and tap water. The dams were administered BPA orally ( $40 \mu \mathrm{g}$ BPA $/ \mathrm{kg}$ body weight per day, Sigma-Aldrich Co.) or vehicle (water, $1 \%$ in ethanol) throughout pregnancy and lactation, using cornflakes as the carrier (Poimenova et al. 2010) in order to avoid stress to the animals. The dose was adjusted to body weight changes during pregnancy and lactation. In total, 37 offspring were born in the BPA group (14 males and 23 females) and 48 offspring ( 22 males and 26 females) in the control group. Litters were culled to ten pups.

Published by Bioscientifica Ltd. 
Anogenital distances were measured at postnatal day 1 . All pups were weaned at postnatal day 22. Puberty onset was monitored in female offspring through observation of vaginal opening. At mid-puberty (postnatal day 46), the offspring were dispersed per sex into non-stressed and stressed groups according to a split litter design. In some groups, more than one rat of the same sex and the same litter was included and this was taken into consideration for statistical analyses (litter effect). Four to six animals per group were killed by decapitation under basal conditions, whereas the rest of the animals were subjected to $15 \mathrm{~min}$ of stress and their behavior was video recorded. The stressed animals were killed at 30 or $120 \mathrm{~min}$ from stress onset (5-9 animals/group per time point). All animals were gently handled the last 4 days before the experiment, to adapt them to the tail vein sampling. Tail-vein blood was collected before stress (basal level) and at $30 \mathrm{~min}$ (t30), $60 \mathrm{~min}$ (t60), and $120 \mathrm{~min}$ (t120) from stress onset. Adrenals, hypothalami, and pituitaries were collected for analysis. Vaginal smears were examined after the animals were killed to detect the phase of the estrous cycle in each female rat. Blood collection was always taking place between 0900 and $1300 \mathrm{~h}$.

All animal treatments were carried out in accordance with UK legal requirements on the ethical use of animals and the protocol was approved by the Ethical Committee of the School of Medicine, National and Kapodistrian University of Athens.

\section{Stress procedure and behavioral measures}

The stressor used was acute forced swimming. The 46-dayold rats of the stressed groups were subjected to inescapable swimming for $15 \mathrm{~min}$ in a glass cylinder $(60 \mathrm{~cm}$ height $\times$ $28 \mathrm{~cm}$ in diameter), filled with water $\left(24 \pm 1^{\circ} \mathrm{C}\right)$ to a depth of $40 \mathrm{~cm}$. The water was changed for each animal. At the end of the session, the rat was removed from the cylinder, carefully dried, and returned to its home cage. Animals' behavioral coping was camera recorded and scored through a computer program (Registration, version 1.0.0.) by two independent observers, blindly. The duration of the following behaviors was measured during the first $5 \mathrm{~min}$ of stress: escaping (climbing at the walls, trying to escape), swimming (active swimming without trying to escape), and floating (staying immobile and making only the movements required to keep the head above the water).

\section{RIA}

The blood samples were centrifuged at $10000 \boldsymbol{g}$ for $5 \mathrm{~min}$. Plasma was collected and kept at $-80^{\circ} \mathrm{C}$ until use.
Corticosterone levels were determined by using a standard RIA kit for small rodents (MP Biomedicals LLC, New York, NY, USA; sensitivity $1.25 \mathrm{ng} / \mathrm{ml}$, intra-assay variation $4.4 \%$, interassay variation $6.5 \%$ ).

\section{Adrenal histomorphometry}

Adrenals were weighted and fixed in neutral formalin for $24 \mathrm{~h}$. Paraffin sections $(5 \mu \mathrm{m})$ were cut and stained with hematoxylin and eosin to assess standard histology and morphometry. Central adrenal sections from 6 to 8 adrenals per group were digitized (Leica Microsystems GmbH, Wetzlar, Germany). We calculated the thickness of total cortex and that of zona glomeruloza, fasciculata, and reticularis (Image J v.1.41 software, NIH, Bethesda, MD, USA). Specifically, the length, parallel to the adrenal radius, of these areas was measured in seven different sections per adrenal and the average value per zone, expressed as a percentage of the cortex, was used in final analysis of zone thickness. The cellular density in the outer and the inner parts of the zona fasciculata was determined by measuring the number of cell nuclei (Image J v.1.41 software) in the areas of the zona fasciculata adjacent to the zona glomeruloza and reticularis respectively. The nuclei were counted in eight frames $(125 \times 125$ microns) per adrenal, randomly selected within each sub-area. Measurements were conducted by two independent observers, blindly. Before morphometry, the observers were aided by a pathologist to properly define the borders between the zona fasciculata and reticularis.

\section{Western blot}

Frozen hypothalami were homogenized and the wholecell extract was electrophoresed as previously described (Poimenova et al. 2010). Proteins were transferred to nitrocellulose membranes (Schleicher \& Schuell, Dassel, Germany). According to molecular weights, different parts of the membranes were incubated overnight at $4{ }^{\circ} \mathrm{C}$ with antibodies against GR (MAb-010-050, Diagenode, Liege, Belgium; 1:50; Rao et al. 2011) or GAPDH (Chemicon, Temecula, CA USA; 1:20 000), the latter was used for normalization of protein loading. The signal was visualized by chemiluminescence (ECL kit Amersham) on Fuji Medical X-ray film. Image J v.1.41 software was used to quantify the optical densities on scanned films.

\section{RT-qPCR}

RT followed by quantitative (real time) PCR was used to detect the levels of Crhr1 and Pomc mRNA in the pituitaries.

Published by Bioscientifica Ltd. 
Total RNA was extracted using the Trizol reagent (Life Technologies) according to the manufacturer's instructions. RNA $(1-2 \mu \mathrm{g})$ was reverse transcribed in a buffer containing $50 \mathrm{mM}$ Tris- $\mathrm{HCl} \mathrm{pH}$ 8.3, $75 \mathrm{mM} \mathrm{KCl}, 3 \mathrm{mM} \mathrm{MgCl}, 10 \mathrm{mM}$ dithiothreitol, $500 \mu \mathrm{M}$ each dNTP, $25 \mu \mathrm{g} / \mathrm{ml}$ oligo-dT, $2 \mathrm{U}$ RNasin, and $200 \mathrm{U}$ M-MLV Reverse Transcriptase (Life Technologies) according to manufacturer's instructions. Real-time PCR was performed in 96-well PCR microplates using the iQ SYBR Green Supermix, in an iQ5 thermal cycler (Bio-Rad Laboratories). The thermal cycling conditions comprised a denaturation step at $95{ }^{\circ} \mathrm{C}$ for $3 \mathrm{~min}$ followed by 40 cycles at $95^{\circ} \mathrm{C}$ for $15 \mathrm{~s}$, and $60^{\circ} \mathrm{C}$ for $1 \mathrm{~min}$. The comparative $C_{\mathrm{t}}$ method was used to calculate the relative gene expression by the formula $\left({ }^{2-\Delta \Delta C_{t}}\right)$ for gene expression patterns and the formula $\left({ }^{2-\Delta C_{t}}\right)$ for ratios of gene expression (Schmittgen \& Livak 2008). Expression levels of the genes of interest were normalized to the respective levels of $\beta$-actin (Actb). The following primer pairs were used: rat Crhr1: forward: GCCGCCTACAATTACTTCCA, reverse: CAATGCAGACGAACATCCAC; rat Pomc: forward: 5'-TGTGAAGGTGTACCCCAATG-3', reverse: 5'-TCCAGCTCCCTCTTGAACTC-3'; rat Actb: forward: $5^{\prime}$-CTAAGGCCAACCGTGAAAAG-3', reverse: 5'-GCATACAGGGACAACACAGC-3'.

\section{Statistical analyses}

The Mann-Whitney $U$ test was used for comparisons of sex ratio and vaginal opening. The effect of BPA treatment and sex on adrenals' weight and morphology as well as on stresscoping behavior was examined by using two-way ANOVA. Corticosterone data were analyzed using two-way ANOVA for repeated measures and separate two-way ANOVAs per time point. The least squares differences post-hoc test was used when appropriate. The effect of BPA treatment, sex, and stress on the levels of GR was analyzed by three-way ANOVA. RT-qPCR data were expressed relative to 'control conditions' (non-BPA treated or non-stressed) and were evaluated by independent samples $t$-test. Because more than one same-sex sibling contributed to some experimental groups (with $n>5$ ), the birth litter was added as a covariate in the statistical analyses to correct for a possible effect on the results. Statistical significance was accepted as $P<0.05$.

\section{Results}

\section{Reproductive physiology}

One miscarriage was observed among the BPA-exposed dams at an early stage of pregnancy. The BPA-exposed offspring comprised $38 \%$ males vs $62 \%$ females and the control offspring $45 \%$ males vs $54 \%$ females. Although the ratio of males:females in the offspring of the five BPAtreated dams ranged from $2: 8$ to $2: 1$, male birth rate (median $=2$, range $1-5)$ and female birth rate $($ median $=4$, range $=1-8)$ were not significantly different $(P=0.310)$. In comparison, the ratio of males/females in the offspring of the five vehicle-treated dams, ranged from $4 / 8$ to $6 / 4$ and male birth rate (median $=4$, range 4-6) and female birth rate (median $=5$, range $=3-8$ ) were quite similar comparable $(P=0.548)$.

The dose of BPA used in this experiment had no significant effect on the anogenital distances of same-sex pups, as measured at postnatal day 1 (control males: $4.52 \pm 0.11 \mathrm{~mm}$; BPA-exposed males: $4.29 \pm 0.18 \mathrm{~mm}$; control females: $2.59 \pm 0.08 \mathrm{~mm}$; BPA-exposed females: $2.74 \pm 0.09 \mathrm{~mm} ; P=0.25$ and $P=0.19$ respectively; $t$-test). The same was true for the time of vaginal opening (control females: median, 35 days; BPA-exposed females: median, 34 days; $P=0.263$ ). More specifically, $38.5 \%$ of control and $43 \%$ of BPA-exposed females entered puberty during postnatal days $31-33$. During postnatal days $34-36,53.8 \%$ of control and the $52.2 \%$ of BPA-exposed females entered. The rest of the female animals entered puberty during postnatal days 37-38. Vaginal smears at killing of animals exhibited no difference in cyclicity between control and BPA-exposed females. The majority of females $(58 \%$ of controls and $65 \%$ of BPA-treated) were at the estrous phase. The distribution in proestrous, diestrus, and metoestrus equally ranged from 17 to $10 \%$ in both groups. Ovarian morphology was similar between the two groups of females (not shown).

\section{Histology of adrenal glands}

BPA treatment significantly affected adrenal weight of mid-pubertal animals. Two-way ANOVA for treatment and sex, with litter as covariate, showed a significant effect of sex $\left(F_{(1,42)}=21.89, P<0.0001\right)$ and a significant $\operatorname{sex} \times$ treatment interaction $\left(F_{(1,42)}=4.73, P=0.036\right)$ on absolute adrenal weight. Post-hoc analysis revealed that BPA females had heavier adrenals compared with control females $(P=0.038)$ and with BPA-treated males $(P<0.0001)$, whereas the adrenal weight difference in control animals did not reach significance $(P=0.053)$. The use of normalized adrenal/body weights showed, in addition to the aforementioned differences, a significant sex difference between control males and females (Table 1).

BPA significantly affected the histology of the adrenal cortex (Table 1 and Fig. 1). A significant effect of BPA and

Published by Bioscientifica Ltd 
Table 1 BPA effects on rat adrenals. Data are expressed as mean \pm s.E.M. The number of animals used in the analysis is given in parentheses

Adrenal weight absolute (mg)

Adrenal weight relative $(\mathrm{mg} / \mathrm{g}$ body weight)

ZG thickness (percentage of cortex)

ZF thickness (percentage of cortex)

ZR thickness (percentage of cortex)

No. of nuclei in outer ZF

No. of nuclei in inner ZF

\begin{tabular}{c} 
Control male \\
\hline $31.80 \pm 2.17(11)$ \\
$0.25 \pm 0.01(11)$ \\
\\
$5.65 \pm 0.36(7)$ \\
$88.85 \pm 0.55(7)$ \\
$5.10 \pm 0.22(7)$ \\
$60.54 \pm 5.13(5)$ \\
$104.28 \pm 4.61(5)$
\end{tabular}

\begin{tabular}{c}
\hline Control female \\
\hline $38.09 \pm 2.18(12)$ \\
$0.36 \pm 0.02^{\mathrm{b}}(12)$ \\
\\
$5.15 \pm 0.32^{\mathrm{b}}(8)$ \\
$90.28 \pm 0.27^{\mathrm{b}}(8)$ \\
$4.45 \pm 0.17^{\mathrm{b}}(8)$ \\
$53.97 \pm 1.82(6)$ \\
$107.05 \pm 3.07(7)$
\end{tabular}

ZG, zona glomeruloza; ZF, zona fasciculata; ZR, zona reticularis. Differences with $P<0.05$ were classified as significant. ${ }^{a}$ Significant effect of BPA.

${ }^{b}$ Significant effect of sex.

its interaction with sex was detected on the thickness of the zona fasciculata $\left(F_{(1,27)}=42.84, P<0.0001\right.$ and $F_{(1,27)}=8.86$, $P=0.007$ respectively). Post-hoc analysis revealed that the thickness of this zone in BPA-treated males was increased, compared with control males $(P<0.0001)$, control females $(P<0.0001)$, and BPA-exposed females $(P=0.043)$. Control females had more extended zona fasciculata than control males $(P=0.040)$, whereas an opposite sex difference trend was detected between BPA-treated animals. Treatment with BPA and its interaction with sex significantly affected zona reticularis thickness $\left(F_{(1,26)}=108.37, P<0.0001\right)$ and $\left.F_{(1,26)}=6.80, P=0.016\right)$. This zone was decreased in BPA- treated animals compared with same-sex controls $(P<0.0001$, for both). In control, but not in BPA animals, zona reticularis was more extended in males when compared with females $(P=0.032)$. Furthermore, typical zona reticularis, normally comprising of a cellular network with smaller than nuclei than cells of the zona fasiculata was not detected in several regions of adrenals derived from BPA-treated males. Instead, cells from the zona fasciculata were often extended to the medulla. This was also observed in BPA-treated females, but to a lesser degree, compared with males (Fig. 1A, B, C, and D). BPA treatment increased the number of cells in the zona fasciculata, as

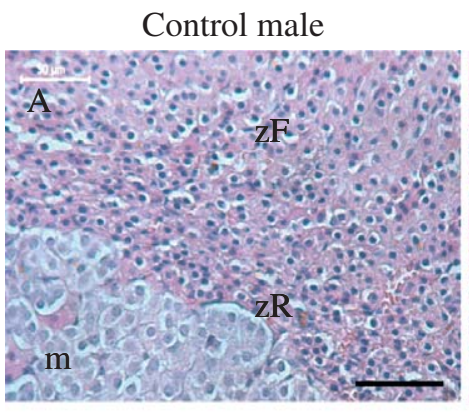

BPA male

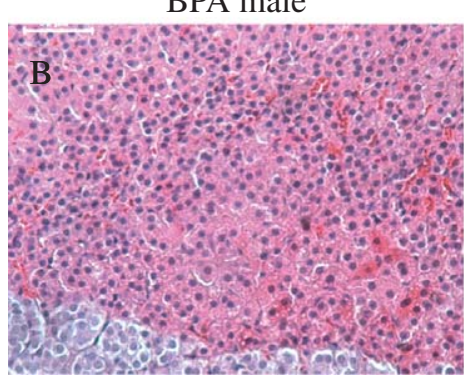

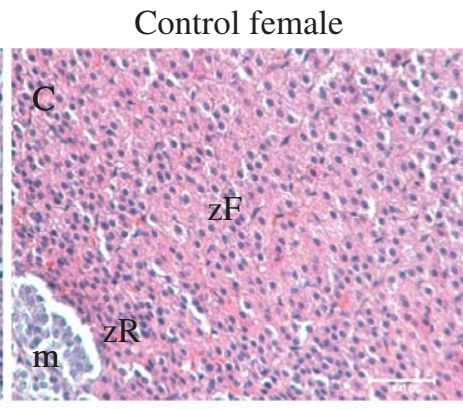

BPA female

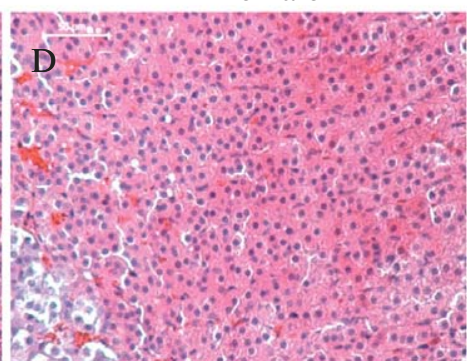

Control female

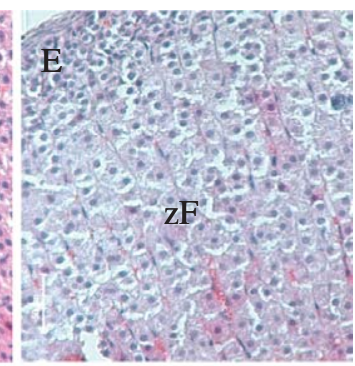

BPA female

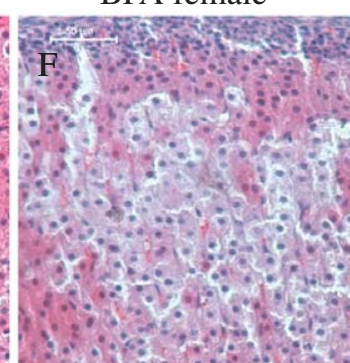

\section{Figure 1}

Representative photomicrographs from the adrenals of untreated controls and BPA-treated rat offspring depicting cortical zones. Zona reticularis (zR) is discrete in controls ( $A$ and $C$ ) but hardly distinguished from zona fasciculata (zF) in BPA-treated animals (B and D) in which large polyhedral
() 2014 Society for Endocrinology Printed in Great Britain cells from the $z F$ extend to the medulla $(m)$. Note the higher number of cells in the inner part of the $\mathrm{zF}$ in BPA-exposed males (B vs $A$ ) and in the outer part of the $z F$ in BPA-exposed females ( $F$ vs $E$ ); hematoxylin and eosin staining. Scale bar $=50 \mu \mathrm{m}$. 
assessed from the counting of nuclei in these mononuclear cells. The number of nuclei in the inner part of the zona fasciculata was significantly affected by $\operatorname{sex}\left(F_{(1,22)}=4.54\right.$, $P=0.047)$ and BPA treatment $\left(F_{(1,22)}=5.24, P=0.034\right.$ and their interaction $\left(F_{(1,22)}=6.59, P=0.019\right)$. BPA-exposed males had higher numbers of nuclei and hence increased cellularity (hyperplasia) in this area (Table 1 and Fig. 1A and B) compared with the control groups ( $P=0.005$ for both) and with BPA-exposed females $(P=0.004)$. Hyperplasia was also detected in the outer zona fasciculata due to BPA treatment $\left(F_{(1,21)}=11.01, P=0.004\right)$ that reached significance in BPAtreated females $(P=0.025)$. The same trend $(P=0.089)$ toward hyperplasia was detected for BPA-treated males compared with control males (Table 1 and Fig. 1E and F).

\section{Behavioral coping}

Treatment with BPA significantly modified the behavior of female rats during forced swimming stress (Fig. 2). Twoway ANOVA showed a significant effect of BPA on the duration of escaping $\left(F_{(1,50)}=10.17, P=0.003\right)$ and floating $\left(F_{(1,50)}=9.41, P=0.004\right)$. Further per sex analysis showed that BPA females spent more time in trying to escape and less time immobile compared with control females, whereas no significant differences were detected in male animals.

\section{Corticosterone secretion}

Repeated-measures ANOVA for the effect of sex and treatment on corticosterone measures before stress (basal level, $0 \mathrm{~min}$ ) and at 30, 60, and $120 \mathrm{~min}$ post stress showed a significant effect of sampling time $\left(F_{(3,30)}=14.73\right.$,

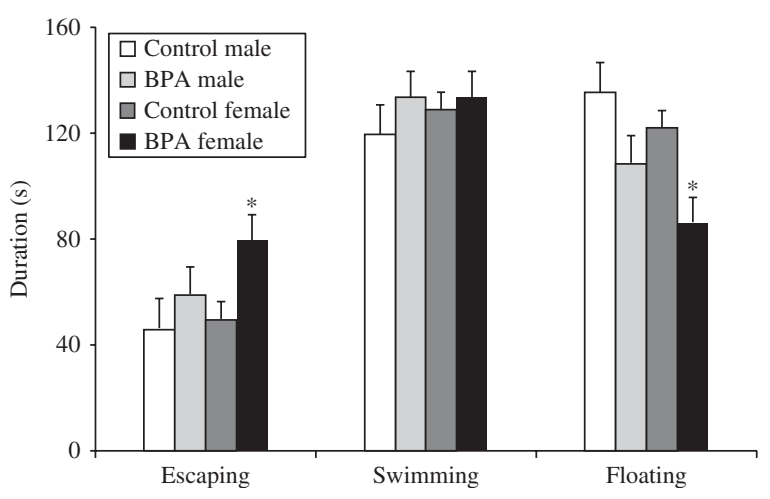

\section{Figure 2}

Behavioral coping of BPA-treated rats and vehicle-treated controls observed during the first 5 min of swimming stress. Data are mean \pm s.E.M. *Significant effect of BPA. Two-way ANOVA. Differences with $P<0.05$ were classified as significant.
$P<0.0001)$ and its interaction with $\operatorname{sex}\left(F_{(3,30)}=11.13\right.$, $P<0.0001)$. Litter was included as covariate. Control males, as well as BPA-exposed males, had significantly increased corticosterone levels at 30 and $60 \mathrm{~min}$ post stress compared with basal levels $(P<0.0001$ for all comparisons) and these returned to baseline levels by $120 \mathrm{~min}$ post stress (Table 2). Similarly, control females displayed increased corticosterone levels at 30 and $60 \mathrm{~min}$ post stress compared with basal levels $(P<0.0001$ and $P=0.026$ respectively) and these returned to baseline levels at $120 \mathrm{~min}$ post stress. Corticosterone in BPA-exposed females was significantly increased from baseline to 30 min post stress $(P<0.0001)$, returned to pre stress levels at $60 \mathrm{~min}(P=0.65)$, and further decreased below baseline levels at 120 min post stress $(P<0.0001)$.

Further analysis within each time point showed that BPA-exposed females had higher basal corticosterone levels than all other groups $(P<0.0001)$. In the controls, no significant sex differences were detected at basal conditions. At $30 \mathrm{~min}$ post stress, both control and BPA-exposed females had higher corticosterone levels than males $(P<0.0001$ and $P=0.001$ respectively), whereas BPA-exposed females had lower hormone levels compared with the control females $(P=0.003)$. At $60 \mathrm{~min}$ post stress, corticosterone levels of BPA-exposed females were significantly lower compared with both control females $(P=0.044)$ and BPA-exposed males $(P=0.046)$. No sex differences were observed in the control groups at $60 \mathrm{~min}$ post stress. At $120 \mathrm{~min}$ post stress, corticosterone levels were higher in BPA-exposed females compared with males $(P=0.043)$.

The fold increase in corticosterone levels for each animal was calculated for the time points of 30,60, and $120 \mathrm{~min}$ post stress, with respect to basal levels (Table 2). Significant sex effects were obtained at $30 \mathrm{~min}\left(F_{(1,24)}=7.17, P=0.014\right)$, $60 \mathrm{~min}\left(F_{(1,18)}=24.09, P<0.0001\right)$, and $120 \mathrm{~min}$ post stress $\left(F_{(1,18)}=8.14, P=0.013\right)$. At 30 min post stress, the mean fold increase in corticosterone was significantly higher in BPAtreated males compared with females $(P=0.011)$, whereas no sex difference was detected in the controls. At 60 min post stress, both male groups exhibited higher increases in corticosterone levels than females $(P=0.04$ for the controls and $P=0.001$ for BPA). At 120 min post stress, BPA-treated males still had a higher fold increase in corticosterone compared with BPA females $(P=0.007)$, whereas no such difference was detected in the controls.

\section{Hypothalamic GR levels}

Three-way ANOVA, with litter as covariate, revealed significant interaction of BPA treatment, sex, and stress

Published by Bioscientifica Ltd 
Table 2 Rat plasma corticosterone concentrations and fold increase during stress. Data represent mean \pm s.E.M. of plasma corticosterone concentrations of control and BPA-treated animals under basal conditions (t0) and at $30 \mathrm{~min}$ ( $t 30), 60 \mathrm{~min}(\mathrm{t} 60)$, and $120 \mathrm{~min}$ ( $\mathrm{t} 120$ ) from stress onset, as well as the fold increase from basal conditions at the aforementioned time points. The number of animals sampled for each group is given in parentheses

Corticosterone
t0 (ng/ml)
t30 (ng/ml)
t60 (ng/ml)
t120 (ng/ml)
t30/t0 (fold increase)
t60/t0 (fold increase)
t120/t0 (fold increase)

\begin{tabular}{c}
\hline Control male \\
\hline $26.87 \pm 6.9(5)$ \\
$587.33 \pm 35.6^{\mathrm{c}}(7)$ \\
$284.12 \pm 29.7^{\mathrm{c}}(5)$ \\
$33.73 \pm 5.9(5)$ \\
$22.66 \pm 3.7(5)$ \\
$9.53 \pm 2.1(4)$ \\
$1.16 \pm 0.4(4)$ \\
\hline
\end{tabular}

\begin{tabular}{c}
\hline BPA male \\
\hline $24.70 \pm 8.7(6)$ \\
$583.63 \pm 43.3^{\mathrm{C}}(7)$ \\
$215.41 \pm 32.7^{\mathrm{C}}(4)$ \\
$23.76 \pm 3.1(5)$ \\
$30.02 \pm 8.2(6)$ \\
$8.71 \pm 2.2(4)$ \\
$1.13 \pm 0.2(4)$
\end{tabular}

\begin{tabular}{c}
\hline Control female \\
\hline $57.21 \pm 8.7(7)$ \\
$1304.81 \pm 126.4^{\mathrm{b}, \mathrm{c}}(10)$ \\
$287.62 \pm 97.1^{\mathrm{c}}(6)$ \\
$65.58 \pm 21.7(6)$ \\
$19.42 \pm 2.5(6)$ \\
$2.95 \pm 1.4^{\mathrm{b}}(4)$ \\
$0.56 \pm 0.2(5)$
\end{tabular}

\begin{tabular}{c}
\hline BPA female \\
\hline $133.51 \pm 17.2^{\mathrm{a}, \mathrm{b}}(9)$ \\
$1027.8 \pm 70.8^{\mathrm{a}, \mathrm{b}, \mathrm{c}}(10)$ \\
$120.10 \pm 24.9^{\mathrm{a}, \mathrm{b}}(7)$ \\
$42.61 \pm 6.1^{\mathrm{b}, \mathrm{c}}(8)$ \\
$8.56 \pm 1.0^{\mathrm{b}}(8)$ \\
$1.00 \pm 0.2^{\mathrm{b}}(7)$ \\
$0.41 \pm 0.06^{\mathrm{b}}(6)$ \\
\hline \hline
\end{tabular}

Significance was accepted for $P<0.05$.

a Significant effect of BPA.

bignificant effect of sex.

'Significant change from basal (t0).

on GR protein levels in the hypothalamus $\left(F_{(1,34)}=7.61\right.$, $P=0.001)$. Subsequent comparisons showed that under basal conditions BPA-treated females had reduced GR levels compared with control females $(P<0.0001)$. Control females had higher GR levels than control males $(P<0.0001)$, whereas no sex differences were seen in BPA-treated animals (Fig. 3). At $120 \mathrm{~min}$ post stress, control females had reduced GR levels $(P=0.008)$ compared with prestress conditions. No significant changes from basal values were observed for control males and the BPA-treated animals following stress.

\section{Pituitary Pomc and Crhr1 levels}

The mRNA levels of Crhr1 in the pituitary did not differ significantly between control and BPA-treated animals of the same sex under basal conditions (Fig. 4A). Control males showed a trend $(P=0.07)$ toward reduced Crhr1 mRNA levels at 30 min compared with non-stressed levels that reached significance at $120 \mathrm{~min}$ post stress $(P=0.002)$. In contrast, BPA-treated males retained prestress levels of Crhr 1 mRNA at 30 and 120 min following stress, as no differences between basal and post-stress levels were detected in this group. Crhr1 mRNA levels were found to be significantly higher at $2 \mathrm{~h}$ from stress onset in BPAexposed males compared with the respective control male group $(P=0.027)$. At $30 \mathrm{~min}$ post stress, both female groups had significantly decreased Crhr1 mRNA levels compared with basal $(P=0.016$ and $P=0.002$ for controls and BPA respectively). This decrease in female groups was also detected at $120 \mathrm{~min}$ post stress $(P=0.005$ and $P=0.021$ for controls and BPA respectively). Comparisons between female animals at 30 and 120 min post stress showed no significant differences due to BPA treatment.
The mRNA levels of Pomc did not differ significantly between control and BPA-treated animals, independently of sex, under basal conditions and at $30 \mathrm{~min}$ after stress (Fig. 4B). Pomc levels were increased at $120 \mathrm{~min}$ following stress in BPA-treated males compared with the same group without stress $(P=0.007)$ as well as with stressed males not treated with BPA $(P=0.01)$. In contrast, BPA-exposed females following stress did not differ from BPA-exposed females not exposed to stress or from control females.

\section{Summary of results}

Continuous BPA exposure during the perinatal period led to abnormal adrenal histology including reduced zona reticularis especially in male offspring, hyperplasia of zona fasciculata in both sexes, and increased adrenal weight in female offspring. Under basal conditions, BPA-exposed females had increased plasma corticosterone and reduced GR levels in the hypothalamus compared with controls. BPA-exposed females exhibited an anxiety-like coping during swimming stress. Following stress, BPA-exposed females had a less rigorous corticosterone response and failed to display downregulation of GR in the hypothalamus, as control females did. BPA-exposed males exhibited heightened corticosterone stress response compared with females. Following stress, BPA-exposed males retained the prestress levels of Crhr1 mRNA and increased Pomc mRNA levels in the pituitary compared with all other groups.

\section{Discussion}

The current study provides evidence that continuous perinatal BPA exposure at a dose similar to the environmentally

Published by Bioscientifica Ltd 

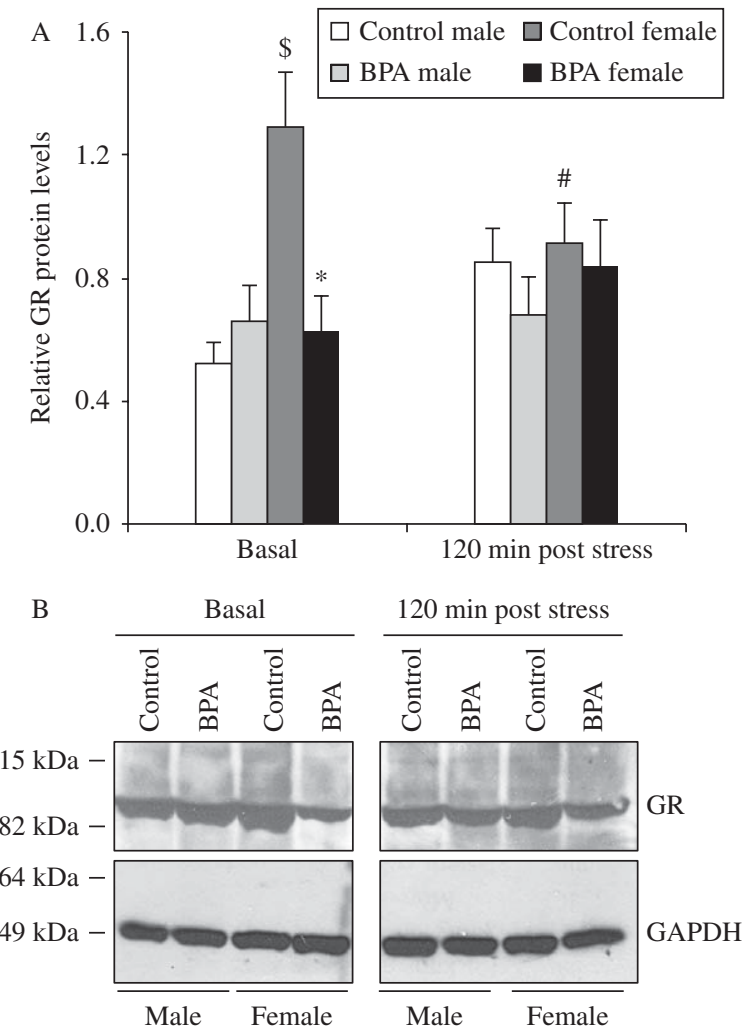

Figure 3

Effect of BPA treatment, sex, and stress on basal and 120 min post stress protein levels of glucocorticoid receptor (GR) in the hypothalamus of mid-adolescent rats. (A) Quantification of the western blot data. Relative protein levels refer to GR levels relative to GAPDH levels as calculated by densitometry of western blot analysis of total protein extract. Data represent mean \pm s.E.M. * Significant effect of BPA; ${ }^{\$}$ significant effect of sex; \#significant effect of stress. Three-way ANOVA. Differences with $P<0.05$ were classified as significant. (B) Representative western blots.

relevant human exposure (Vandenberg et al. 2007) induces long-lasting alterations in the HPA axis of the rat. The effect on the HPA axis of pubertal offspring was apparent in both peripheral and central components of the axis and was sexually dimorphic. The BPA dose used in our study is below the reference dose of $50 \mu \mathrm{g} / \mathrm{kg}$ body weight per day that is the currently accepted LOAEL for humans (US Environmental Protection Agency 1988 Bisphenol A (CASRN 80-05-7). Integrated Risk Information System. Available at www.epa.gov/iris/ subst/0356.htm, accessed Sept 2013). Recent pharmacokinetic studies, taking into account the differences in BPA metabolism between rodents and humans have estimated that exposures to $400 \mu \mathrm{g} / \mathrm{kg}$ body weight per day produce bioactive BPA concentrations in their blood, within the range of recorded human blood concentrations (Vandenberg et al. 2012). Printed in Great Britain

\section{Reproductive physiology}

The perinatal low-dose BPA exposure had no obvious effect on the reproductive physiology of their offspring, as deduced by observations of anogenital distance, puberty onset, ovarian histology and vaginal smears, in agreement with the literature regarding low-dose exposures (Ashby 2001, Rubin et al. 2001, Tinwell et al. 2002, Kubo et al. 2003, Yoshida et al. 2004, Patisaul \& Polston 2008, Poimenova et al. 2010). However, the reduced male:female offspring ratio in BPA-treated dams, though not statistically significant in this study, may imply a male embryo selective vulnerability in utero that worth further investigation.

\section{Adrenal histology and function}

Our observations indicate for the first time, to our knowledge, that continuous low-dose exposure to BPA
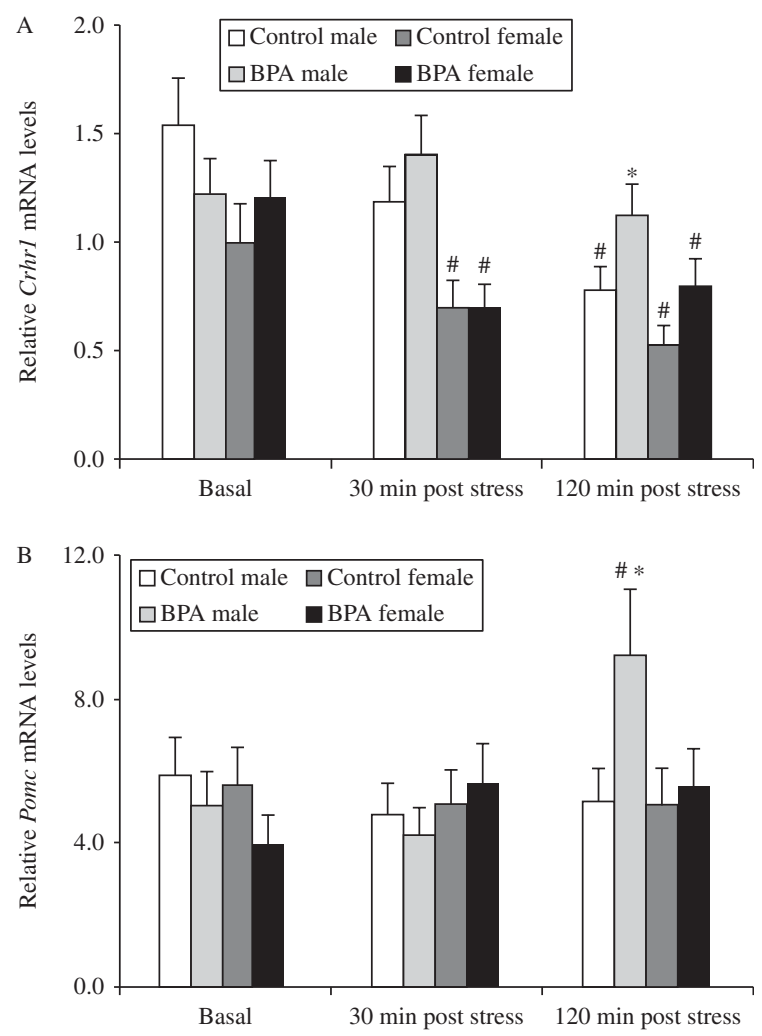

\section{Figure 4}

Effect of BPA treatment, sex, and stress on basal, 30 and 120 min post stress mRNA levels of $\operatorname{Crhr} 1$ (A) and Pomc (B) in the pituitary of mid-adolescent rats. Relative mRNA levels refer to Crhr1 or Pomc mRNA level relative to $A c t b$ mRNA level as calculated by RT-qPCR analyses of total mRNA. Data represent mean \pm s.E.M. * Significant effect of BPA, compared with the 120 min post stress control males; " significant effect of stress compared with the non-stressed (basal) animals of the same sex and BPA treatment groups. Independent samples $t$-test. Differences with $P<0.05$ were classified as significant.

Published by Bioscientifica Ltd. 
may affect adrenal function leading to long-lasting effects on animal's physiology. Fetal adrenal cortex development is dependent on placental estrogen and the existence of both types of estrogen receptors in the fetal gland (Kaludjerovic \& Ward 2012) allows for a genomic action of BPA during developmental exposures. Additional nongenomic or epigenetic BPA actions in the adrenals, already reported for other tissues (Zsarnovszky et al. 2005, Doshi et al. 2011), cannot be excluded. The few reports on the effects of xenoestrogens in the adrenal cortex upon earlylife exposure support their effect on male steroidogenesis. Administration of a high dose of genistein in weanling male rats significantly altered adrenal steroidogenesis at puberty and also expanded the zona fasciculata and reticularis (Ohno et al. 2003). Perinatal exposure to nonylphenol increased adrenal cortex steroidogenic activity and ACTH in male animals only and basal plasma corticosterone in both sexes (Chang et al. 2012), in partial compliance with our corticosterone findings.

Given the importance of normal adrenal development for the feto-placental unit and perinatal survival (Ishimoto \& Jaffe 2011), we cannot exclude the possibility that fetal adrenal abnormalities may have contributed to the reduced number of male offspring from BPA-exposed dams. In addition, the lack of proper cytoarchitecture and the reduced zona reticularis, the main site for extragonadal androgen production, in BPA-treated males, imply a feminizing action of BPA during adrenal gland development that warrants further investigation due to the role of this zone in adrenarche onset and related pathologies in primates (Belgorosky et al. 2008).

\section{Corticosterone responses}

The heavier adrenals of BPA-exposed females vs control females and the extended and hyperplastic zona fasciculata of BPA-treated rats imply alterations in the responsiveness of adrenal cortex to central stress regulators. Indeed, altered corticosterone secretion was witnessed, compared with the non-treated rats, both under basal conditions and following stress, which was sexually dimorphic. Under resting conditions, BPA-treated females had higher basal corticosterone levels than control females and BPA-treated males, in agreement with our previous findings (Poimenova et al. 2010), whereas no sex differences were detected between control animals. The lack of sex differences in plasma corticosterone levels of the untreated controls is in compliance with the literature for pubertal rats, reporting that sex differences in this system normally emerge after puberty (Sencar-Cupovic \&
Milkovic 1976, Romeo 2010). Following stress, BPAtreated females exhibited a blunted stress response at 30 min compared with control females; in contrast to BPAtreated males, which responded similarly to control males. The stress-induced corticosterone levels reported here are in close agreement with the high values reported in the literature for pubertal corticosterone responses (Bourke \& Neigh 2011, Foilb et al. 2011). Previous studies have shown that prepubertal rats irrespective of sex have a protracted corticosterone response to stress compared with adults and that at both ages females demonstrate a higher peak and a faster return to baseline than males (Romeo et al. $2004 a, b)$. Our observations for control rats are in agreement with the results of the aforementioned studies, whereas BPA-exposed females showed an even faster return than controls. Interestingly, chronic exposure of neonatal female rats to estradiol led to increased corticosterone levels and HPA axis hyperactivity under resting conditions (Patchev et al. 1995), suggesting similarities in programming actions of estradiol and BPA.

\section{HPA axis responsiveness and behavioral phenotype}

The interpretation of the adrenal, hormonal, and neuroendocrine findings of this study indicates that the HPA axis of female BPA-exposed offspring under basal conditions is hyperactive, resulting in increased circulating corticosterone that leads to a reduction in GR levels by a process termed homologous downregulation (Oakley \& Cidlowski 1993), consequently limiting cellular responsiveness to glucocorticoids. The blunted span of glucocorticoid response is expected to disturb regulatory circuits involving adrenals, hypothalamus, and pituitary. The dysfunctional adrenal provides more corticosterone than needed. The moderately increased basal corticosterone levels of BPA-exposed females are probably capable of activating hypothalamic GR, resulting in constitutive translocation and blunted recycling of the receptor. This appears to have resulted in the 'atypical,' for resting conditions, autologous downregulation of GR (Oakley \& Cidlowski 1993). The hyperactive HPA axis of BPAexposed females under basal conditions is reflected in their behavioral stress response during the first $5 \mathrm{~min}$ of exposure to swim stress, characterized by increased anxiety-like behavior (escaping) and concomitant reduction of immobility.

In line with the results expected for animals with a dysfunctional HPA axis, BPA-exposed females following stress did not display downregulation of GR levels in response to the stress-induced corticosterone increase,

Published by Bioscientifica Ltd. 
as control females do, toward termination of axis activation (Makino et al. 1995). Heightened levels of glucocorticoids or impaired CRH signaling during adolescence have been proposed to modify brain plasticity and emotionality (Sapolsky 2003) resulting in increased susceptibility to stress-related psychopathologies in adulthood (Becker et al. 2007). Accordingly, the biological outcome of the observed HPA axis deregulation in BPAexposed females may be a sustained inability to successfully cope with stressful events.

Compared with females, pubertal BPA-exposed males exhibited a more active HPA axis under stress, reflected in their high and extended rise in plasma corticosterone and in their higher pituitary Crhr1 and Pomc levels following stress. This sex difference may relay on the potent pituitary signals of BPA-exposed males driving corticosterone secretion and the proper response of their hypertropic and extended zona fasciculata. In comparison with control males in our study, BPA-exposed males appear less mature regarding their pituitary stress responsiveness. According to Foilb et al. (2011), the stress-induced ACTH response is more robust and extended in prepubertal than mature male rats, reaching adult levels after postnatal day 50.

\section{Sexual dimorphism of BPA effects on the stress axis}

Perinatal BPA exposure often exerts a sex-specific effect on their offspring's physiology and behavior, including reduction or reversal of existing sex differences (Richter et al. 2007). In this study, sexually dimorphic effects of BPA on the HPA axis components were observed that may have contributed to sex differences in stress responsiveness. BPA acting as a weak estrogen could have modified the steroidogenic activity or sensitivity of the developing adrenal cortex to pituitary signals in a sex-specific way. Accordingly, we could detect sexdependent, BPA-induced alterations of adrenal histology, able to alter corticosterone secretion and stress responses of the exposed animals. In addition, sex-specific alterations were detected in pituitary and hypothalamic mediators of BPA-treated animals, further supporting this hypothesis.

Circulating gonadal hormones can modulate adult HPA reactivity (Handa et al. 1994, Viau \& Meaney 1996, Viau 2002), but they did not seem to mediate stress responses in rats younger than 50 days (Foilb et al. 2011). Nonetheless, to exclude the possibility that the detected BPA effects on HPA axis reflect alterations in gonadal steroids of the exposed animals, we have previously
(Poimenova et al. 2010) determined the circulating levels of progesterone and testosterone in mid-pubertal BPA-exposed rats treated under the same protocol. No differences were found between BPA-exposed and control animals, in compliance with previous studies (Ramos et al. 2003, Muñoz-de-Toro et al. 2005). In addition, in this study, monitoring of the estrous cycle also did not reveal differences between control and BPA-treated females that could possibly influence stress responses.

\section{Limitations of the study}

This study has limitations mainly due to the low number of births ( $n=5$ per treatment), which did not allow equilibrated sex ratios in BPA-exposed litters. This could have possibly biased maternal care, subsequently affecting some physiological outcomes (Meaney 2001). In a previous study (Della Seta et al. 2005), maternal care was affected in dams treated with $40 \mu \mathrm{g} \mathrm{BPA} / \mathrm{kg}$ body weight per day, but this was not influenced by the sex of the pup, in contrast to the control dams. In a more recent study (Kundakovic et al. 2013), the maternal behavior of dams exposed to BPA during pregnancy, at a dose similar to that used in our study, did not differ from normal. Furthermore, in the same study, the modified maternal care at BPA doses lower or higher than ours did not affect the BPAinduced effects on offspring gene expression. A bigger sample would have also allowed the use of more than one BPA dose to examine the 'non-monotonic' curve of BPA actions previously reported (Vandenberg et al. 2007). Finally, more studies are required to examine whether the observed alterations in the pubertal HPA axis are retained or modified in the adult state, under the influence of the gonadal steroids.

In conclusion, continuous exposure of rats in early life to BPA at a dose that is lower than the currently accepted LOAEL $(50 \mu \mathrm{g} / \mathrm{kg})$ can modify basal and stress-induced HPA axis function at puberty in a sexually dimorphic way. This implicates BPA in aberrant HPA axis programming, potentially leading to stress-related disorders in later life.

\section{Declaration of interest}

The authors declare that there is no conflict of interest that could be perceived as prejudicing the impartiality of the research reported.

\section{Funding}

This research was funded in part by Marie Curie Early Stage Training project 'EURODESY' (contract MEST-CT-2005-020575).

Published by Bioscientifica Ltd. 


\section{Acknowledgements}

The authors acknowledge the expertise of $\mathrm{Dr}$ I Chatzistamou, NKUA pathologist, in adrenal histology.

\section{References}

Ashby J 2001 Increasing the sensitivity of the rodent uterotrophic assay to estrogens, with particular reference to bisphenol A. Environmental Health Perspectives 109 1091-1094. (doi:10.1289/ehp.011091091)

Becker JB, Monteggia LM, Perrot-Sinal TS, Romeo RD, Taylor JR, Yehuda R $\&$ Bale TL 2007 Stress and disease: is being female a predisposing factor? Journal of Neuroscience 27 11851-11855. (doi:10.1523/JNEUROSCI. 3565-07.2007)

Belgorosky A, Baquedano MS, Guercio G \& Rivarola MA 2008 Adrenarche: postnatal adrenal zonation and hormonal and metabolic regulation. Hormone Research 70 257-267. (doi:10.1159/000157871)

Bourke CH \& Neigh GN 2011 Behavioral effects of chronic adolescent stress are sustained and sexually dimorphic. Hormones and Behavior 60 112-120. (doi:10.1016/j.yhbeh.2011.03.011)

Braun JM, Yolton K, Dietrich KN, Hornung R, Ye X, Calafat AM \& Lanphear BP 2009 Prenatal bisphenol A exposure and early childhood behavior. Environmental Health Perspectives 117 1945-1952. (doi:10. 1289/ehp.0900979)

Braun JM, Kalkbrenner AE, Calafat AM, Yolton K, Ye X, Dietrich KN \& Lanphear BP 2011 Impact of early-life bisphenol A exposure on behavior and executive function in children. Pediatrics 128 873-882. (doi:10.1542/peds.2011-1335)

Calafat AM, Ye X, Wong LY, Reidy JA \& Needham LL 2008 Exposure of the U.S. population to bisphenol A and 4-tertiary-octylphenol: 2003-2004. Environmental Health Perspectives 116 39-44. (doi:10.1289/ehp.10753)

Carr R, Bertasi F, Betancourt A, Bowers S, Gandy BS, Ryan P \& Willard S 2003 Effect of neonatal rat bisphenol A exposure on performance in the morris water maze. Journal of Toxicology and Environmental Health. Part A 14 2077-2088. (doi:10.1080/713853983)

Carrasco GA \& Van de Kar LD 2003 Neuroendocrine pharmacology of stress. European Journal of Pharmacology 463 235-272. (doi:10.1016/ S0014-2999(03)01285-8)

Chang L-L, Wun W-S \& Wang PS 2012 In utero and neonate exposure to nonylphenol develops hyperadrenalism and metabolic syndrome later in life. I. first generation rats (F1). Toxicology 301 40-49. (doi:10.1016/ j.tox.2012.06.017)

Della Seta D, Minder I, Dessì-Fulgheri F \& Farabollini F 2005 Bisphenol-A exposure during pregnancy and lactation affects maternal behavior in rats. Brain Research Bulletin 65 255-260. (doi:10.1016/j.brainresbull. 2004.11.017)

Doshi T, Mehta SS, Dighe V, Balasinor N \& Vanage G 2011 Hypermethylation of estrogen receptor promoter region in adult testis of rats exposed neonatally to bisphenol A. Toxicology 289 74-82. (doi:10.1016/ j.tox.2011.07.011)

Farabollini F, Porrini S \& Dessì-Fulgheri F 1999 Perinatal exposure to the estrogenic pollutant bisphenol A affects behavior in male and female rats. Pharmacology Biochemistry and Behavior 64 687-694. (doi:10.1016/ S0091-3057(99)00136-7)

Foilb AR, Lui P \& Romeo RD 2011 The transformation of hormonal stress responses throughout puberty and adolescence. Journal of Endocrinology 210 391-398. (doi:10.1530/JOE-11-0206)

Funabashi T, Kawaguchi M, Furuta M, Fukushima A \& Kimura F 2004 Exposure to bisphenol A during gestation and lactation causes loss of sex difference in corticotropin-releasing hormone-immunoreactive neurons in the bed nucleus of the stria terminalis of rats. Psychoneuroendocrinology 29 475-485. (doi:10.1016/S0306-4530(03)00055-6)

Handa RJ, Burgess LH, Kerr JE \& O’Keefe JA 1994 Gonadal steroid hormone receptors and sex differences in the hypothalamo-pituitary-adrenal axis. Hormones and Behavior 28 464-476. (doi:10.1006/hbeh.1994.1044)
Ishimoto H \& Jaffe RB 2011 Development and function of the human fetal adrenal cortex: a key component in the fetoplacental unit. Endocrine Reviews 32 317-355. (doi:10.1210/er.2010-0001)

Joëls M, Sarabdjitsingh RA \& Karst H 2012 Unraveling the time domains of corticosteroid hormone influences on brain activity: rapid, slow, and chronic modes. Pharmacological Reviews 64 901-938. (doi:10.1124/pr. 112.005892)

Kaludjerovic J \& Ward WE 2012 The interplay between estrogen and fetal adrenal cortex. Journal of Nutrition and Metabolism 2012837901. (doi:10.1155/2012/837901)

Kawai K, Takehiro N, Nishikata H, Aou S, Takii M \& Kubo C 2003 Aggressive behavior and serum testosterone concentration during the maturation process of male mice: the effects of fetal exposure to bisphenol A. Environmental Health Perspectives 111 175-178. (doi:10.1289/ehp.5440)

Khurana S, Ranmal S \& Ben-Jonathan N 2000 Exposure of newborn male and female rats to environmental estrogens: delayed and sustained hyperprolactinemia and alterations in estrogen receptor expression. Endocrinology 141 4512-4517. (doi:10.1210/en.141.12.4512)

de Kloet ER, Joëls M \& Holsboer F 2005a Stress and the brain: from adaptation to disease. Nature Reviews. Neuroscience 6 463-475. (doi:10.1038/nrn1683)

de Kloet ER, Sibug RM, Helmerhorst FM \& Schmidt MV 2005 $b$ Stress, genes and the mechanism of programming the brain for later life. Neuroscience and Biobehavioral Reviews 29 271-281. (doi:10.1016/ j.neubiorev.2004.10.008)

Kubo K, Arai O, Ogata R, Omura M, Hori T \& Aou S 2001 Exposure to bisphenol A during the fetal and suckling periods disrupts sexual differentiation of the locus coeruleus and of behavior in the rat. Neuroscience Letters 304 73-76. (doi:10.1016/S0304-3940(01)01760-8)

Kubo K, Arai O, Omura M, Watanabe R, Ogata R \& Aou S 2003 Low dose effects of bisphenol A on sexual differentiation of the brain and behavior in rats. Neuroscience Research 45 345-356. (doi:10.1016/S01680102(02)00251-1)

Kundakovic M, Gudsnuk K, Franks B, Madrid J, Miller RL, Perera FP \& Champagne FA 2013 Sex-specific epigenetic disruption and behavioral changes following low-dose in utero bisphenol A exposure. PNAS 110 9956-9961. (doi:10.1073/pnas.1214056110)

Makino S, Schulkin J, Smith MA, Pacák K, Palkovits M \& Gold PW 1995 Regulation of corticotropin-releasing hormone receptor messenger ribonucleic acid in the rat brain and pituitary by glucocorticoids and stressglucocorticoids and stress. Endocrinology 136 4517-4525. (doi:10.1210/en.136.10.4517)

Meaney MJ 2001 Maternal care, gene expression, and the transmission of individual differences in stress reactivity across generations. Annual Reviews in Control Neuroscience 24 1161-1192. (doi:10.1146/annurev. neuro.24.1.1161)

Miyagawa K, Narita M, Narita M, Akama H \& Suzuki T 2007 Memory impairment associated with a dysfunction of the hippocampal cholinergic system induced by prenatal and neonatal exposures to bisphenol-A. Neuroscience Letters 418 236-241. (doi:10.1016/j.neulet. 2007.01.088)

Müller MB, Preil J, Renner U, Zimmermann S, Kresse AE, Stalla GK, Keck ME, Holsboer F \& Wurst W 2001 Expression of CRHR1 and CRHR2 in mouse pituitary and adrenal gland: implications for HPA system regulation. Endocrinology 142 4150-4153. (doi:10.1210/en.142.9.4150)

Muñoz-de-Toro M, Markey CM, Wadia PR, Luque EH, Rubin BS, Sonnenschein C \& Soto AM 2005 Perinatal exposure to bisphenol-A alters peripubertal mammary gland development in mice. Endocrinology 146 4138-4147. (doi:10.1210/en.2005-0340)

Oakley RH \& Cidlowski JA 1993 Homologous down regulation of the glucocorticoid receptor: the molecular machinery. Critical Reviews in Eukaryotic Gene Expression 3 63-88.

Ohno S, Nakajima Y, Inoue K, Nakazawa H \& Nakajin S 2003 Genistein administration decreases serum corticosterone and testosterone levels in rats. Life Sciences $\mathbf{7 4}$ 733-742. (doi:10.1016/j.lfs.2003.04.006) http://joe.endocrinology-journals.org DOI: $10.1530 / J O E-13-0416$
() 2014 Society for Endocrinology Printed in Great Britain 
Patchev VK, Hayashi S, Orikasa C \& Almeida OFX 1995 Implications of estrogen-dependent brain organization for gender differences in hypothalamopituitary-adrenal regulation. FASEB Journal 9 419-423.

Patisaul HB \& Polston EK 2008 Influence of endocrine active compounds on the developing rodent brain. Brain Research Reviews 7 352-362. (doi:10.1016/j.brainresrev.2007.06.008)

Perera F, Vishnevetsky J, Herbstman JB, Calafat AM, Xiong W, Rauh V \& Wang S 2012 Prenatal bisphenol a exposure and child behavior in an innercity cohort. Environmental Health Perspectives 120 1190-1194. (doi:10.1289/ehp.1104492)

Poimenova A, Markaki E, Rahiotis C \& Kitraki E 2010 Corticosteroneregulated actions in the rat brain are affected by perinatal exposure to low dose of bisphenol A. Neuroscience 167 741-749. (doi:10.1016/ j.neuroscience.2010.02.051)

Ramos JG, Varayoud J, Kass L, Rodríguez H, Costabel L, Munoz-de-Toro M \& Luque EH 2003 Bisphenol A induces both transient and permanent histofunctional alterations of the hypothalamic-pituitary-gonadal axis in prenatally exposed male rats. Endocrinology 144 3206-3215. (doi:10.1210/en.2002-0198)

Rao NA, McCalman MT, Moulos P, Francoijs KJ, Chatziioannou A, Kolisis FN, Alexis MN, Mitsiou DJ \& Stunnenberg HG 2011 Coactivation of GR and NFKB alters the repertoire of their binding sites and target genes. Genome Research 21 1404-1416. (doi:10.1101/gr. 118042.110)

Richter CA, Birnbaum LS, Farabollini F, Newbold RR, Rubin BS, Talsness CE, Vandenbergh JG, Walser-Kuntz DR \& vom Saal FS 2007 In vivo effects of bisphenol A in laboratory rodent studies. Reproductive Toxicology $\mathbf{2 4}$ 199-224. (doi:10.1016/j.reprotox.2007.06.004)

Romeo RD 2010 Pubertal maturation and programming of hypothalamicpituitary-adrenal reactivity. Frontiers in Neuroendocrinology 31 232-240. (doi:10.1016/j.yfrne.2010.02.004)

Romeo RD, Lee SJ, Chhua N, McPherson CR \& McEwen BS $2004 a$ Testosterone cannot activate an adult-like stress response in prepubertal male rats. Neuroendocrinology 79 125-132. (doi:10.1159/ 000077270)

Romeo RD, Lee SJ \& McEwen BS 2004b Differential stress reactivity in intact and ovariectomized prepubertal and adult female rats. Neuroendocrinology 80 387-393. (doi:10.1159/000084203)

Rubin BS, Murray MK, Damassa DA, King JC \& Soto AM 2001 Perinatal exposure to low doses of bisphenol A affects body weight patterns of estrous cyclicity, and plasma LH levels. Environmental Health Perspectives 109 675-680. (doi:10.1289/ehp.01109675)

Rubin BS, Lenkowski JR, Schaeberle CM, Vandenberg LN, Ronsheim PM \& Soto AM 2006 Evidence of altered brain sexual differentiation in mice exposed perinatally to low, environmentally relevant levels of bisphenol A. Endocrinology 147 3681-3691. (doi:10.1210/en.20060189)

Sapolsky RM 2003 Stress and plasticity in the limbic system. Neurochemical Research 28 1735-1742. (doi:10.1023/A:1026021307833)

Schmittgen TD \& Livak KJ 2008 Analyzing real-time PCR data by the comparative $C_{\mathrm{T}}$ method. Nature Protocols 3 1101-1108. (doi:10.1038/ nprot.2008.73)

Seale JV, Wood SA, Atkinson HC, Lightman SL \& Harbuz MS 2005 Organizational role for testosterone and estrogen on adult hypothalamic-pituitary-adrenal axis activity in the male rat. Endocrinology 146 1973-1982. (doi:10.1210/en.2004-1201)

Sencar-Cupovic I \& Milkovic S 1976 The development of sex differences in the adrenal morphology and responsiveness in stress of rats from birth to the end of life. Mechanisms of Ageing and Development 5 1-9. (doi:10.1016/0047-6374(76)90002-6)

Szyf M, Weaver IC, Champagne FA, Diorio J \& Meaney MJ 2005 Maternal programming of steroid receptor expression and phenotype through DNA methylation in the rat. Frontiers in Neuroendocrinology 26 139-162. (doi:10.1016/j.yfrne.2005.10.002)

Tinwell H, Haseman J, Lefevre PA, Wallis N \& Ashby J 2002 Normal sexual development of two strains of rat exposed in utero to low doses of bisphenol A. Toxicological Sciences 68 339-348. (doi:10.1093/toxsci/68. 2.339)

Vandenberg LN, Hauser R, Marcus M, Olea N \& Welshons WV 2007 Human exposure to bisphenol A (BPA). Reproductive Toxicology 24 139-177. (doi:10.1016/j.reprotox.2007.07.010)

Vandenberg LN, Maffini MV, Sonnenschein C, Rubin BS \& Soto AM 2009 Bisphenol-A and the great divide: a review of controversies in the field of endocrine disruption. Endocrine Reviews 30 75-95. (doi:10.1210/er. 2008-0021)

Vandenberg LN, Colborn T, Hayes TB, Heindel JJ, Jacobs DR Jr, Lee DH, Shioda T, Soto AM, vom Saal FS, Welshons WV et al. 2012 Hormones and endocrine-disrupting chemicals: low dose effects and nonmonotonic dose responses. Endocrine Reviews 33 378-455. (doi:10.1210/er. 2011-1050)

Viau V 2002 Functional cross-talk between the hypothalamic-pituitarygonadal and -adrenal axes. Journal of Neuroendocrinology 14 506-513. (doi:10.1046/j.1365-2826.2002.00798.x)

Viau V \& Meaney MJ 1996 The inhibitory effect of testosterone on hypothalamic-pituitary-adrenal responses to stress is mediated by the medial preoptic area. Journal of Neuroscience 16 1866-1876.

Weinstock M 2008 The long-term behavioural consequences of prenatal stress. Neuroscience and Biobehavioral Reviews 32 1073-1086. (doi:10.1016/j.neubiorev.2008.03.002)

Welshons WV, Nagel SC \& vom Saal FS 2006 Large effects from small exposures. III. Endocrine mechanisms mediating effects of bisphenol A at levels of human exposure. Endocrinology 147 S56-S69. (doi:10.1210/ en.2005-1159)

Xu X, Liu Y, Sadamatsu M, Tsutsumi S, Akaike M, Ushijima H \& Kato N 2007 Perinatal bisphenol A affects the behavior and SRC-1 expression of male pups but does not influence on the thyroid hormone receptors and its responsive gene. Neuroscience Research 58 149-155. (doi:10.1016/j.neures.2007.02.011)

Yoshida M, Shimomoto T, Katashima S, Watanabe G, Taya K \& Maekawa A 2004 Maternal exposure to low doses of bisphenol A has no effects on development of female reproductive tract and uterine carcinogenesis in Donryu rats. Journal of Reproduction and Development 50 349-360. (doi:10.1262/jrd.50.349)

Zsarnovszky A, Le HH, Wang H-S \& Belcher SM 2005 Ontogeny of rapid estrogen-mediated extracellular signal-regulated kinase signaling in the rat cerebellar cortex: potent nongenomic agonist and endocrine disrupting activity of the xenoestrogen bisphenol A. Endocrinology 146 5388-5396. (doi:10.1210/en.2005-0565)

Received in final form 4 December 2013

Accepted 9 December 2013

Accepted Preprint published online 9 December 2013 http://joe.endocrinology-journals.org DOI: $10.1530 / J O E-13-0416$
() 2014 Society for Endocrinology Printed in Great Britain 